\title{
EXPLORANDO EL ACONTECIMIENTO HISTÓRICO. (EL CASO DEL MOTÍN DEL PENAL EL SEXTO DE 1984)
}

\author{
Carlos A. De la Cruz Villanueva
}

\begin{abstract}
RESUMEN
La siguiente investigación esboza una comprensión preliminar del acontecimiento histórico a través del breve análisis a uno, el motín en el penal "El Sexto" desarrollado el 27 de marzo de 1984, el cual impactó en la sociedad limeña. Para ello nos aproximaremos, a qué entendemos por acontecimiento histórico; y cómo a través de sus características es reforzado y construido por la sociedad. Además de apreciar el valor de la fuente en la investigación y como se ellas se convierten en agente de la historia pues influyen y estimulan ciertas actitudes mentales, además de ser resonancia y reproductora de ciertos sucesos sociales lo cual contribuye en la construcción o refuerzo de una versión histórica con respecto a ciertos eventos distantes en el tiempo.
\end{abstract}

Palabras ClaVE: Construcción histórica, acontecimiento histórico, agente de la historia, motín en el penal "El Sexto".

\section{EXPLORING THE HISTORICAL EVENT. (THE CASE THE RIOT IN THE PRISON “EL SEXTO” 1984)}

\begin{abstract}
The following outlines show a preliminary investigation understanding of historical events, along the years and focusing in one of them. The riot in the prison "El Sexto" occured on March 27, 1984 which impacted on Lima society, for this we will approach in the time so it is necessary to be aware about this historical event and its own characteristics that is strengthen and built by the society. Besides appreciating the importance of the news sources in the research and as they become agent of history as influence and stimulate certain mental attitudes, besides being resonance and breeding of certain social events which contribute in building or strengthening a historical version with respect to certain distant events in time.
\end{abstract}

KEYWORDS: historical building, historical event, agent of history, riot in the prison"El Sexto". 
"... descubrirás que muchas de las verdades que aceptamos y decimos dependen de cierto punto de vista." 1

"... You will find that many of the truths we accept and say depend on certain viewpoint."

\section{A manera de introducción e ideas preliminares}



a historia existe gracias a la unión de dos partes. La primera, el transcurrir de la sociedad a través del tiempo y del espacio, del cual sabemos a través de nuestras construcciones que dejamos, paso a paso, elementos testimoniales (llamados fuentes), que en forma consciente e inconscientemente son huellas de nuestro recorrido en este mundo; estas fuentes son diversas, complejas en su naturaleza, y por ello requieren un tratamiento especializado. La segunda parte es el historiador, una entidad compleja en todo el sentido de la palabra, pues él realiza con su trabajo una aproximación a la comprensión de la sociedad a través del tiempo, para ello recurre a las diversas fuentes, las cuales acopia, selecciona, sistematiza, analiza y evalúa para poder lograr dicha labor. Pero para realizar ello tiene que tener en cuenta ciertos elementos que a continuación mencionaré y explicaré brevemente:

\section{La subjetividad}

El historiador es un ser social dotado de una gran capacidad de acopiar, integrar y analizar información que le ayude a comprender o evaluar a la sociedad a través del tiempo y del espacio, ello a partir de una construcción discursiva en la cual se entreteje sus motivaciones personales, las del grupo al cual pertenece y las necesidades sociales expresadas en el tiempo en que vive. Además, combina intencionalidades o corrientes ya sean filosóficas, teóricas, narrativas en el relato que constituye.

En este recorrido, al parecer tan sencillo, posee una complejidad que en principio y a pesar de haber transcurrido ya muchas décadas de una ardua crítica cientificista en la cual se cuestionaba la validez de nuestras aproximaciones, se mantiene el cuestionamiento a la subjetividad de la labor y por ende el resultado. Situación que es cierta e importante en el desenvolvimiento de nuestra labor, ello implica que no debemos negar el hecho de ser seres subjetivos, pero sí comprender y sobre todo defender y explicar los alcances que significa serlo.

Con respecto a ello el historiador ya ha reflexionado y ha planteado las aristas y limitaciones de ser un ser subjetivo. En principio la crítica desde el siglo XIX es que el historiador si no regula su relato se deja llevar por sus sentimientos, se apasiona y, por ende, distorsiona su narración. Lo cierto es que el historiador utiliza su subjetividad desde la elección de la investigación y desde el desarrollo de causalidad en su investigación, es

1 Frase pronunciada por Sir Alec Guinnes en el papel de Obi Wan Kenobi de la saga épico futurista Star Wars, episodio VI. El regreso del Jedi. 20 Century Fox. USA. Año 1983. 
decir, la subjetividad está presente en todo el proceso de elaboración de su investigación, a la cual en forma discreta la limitamos con método, metodología, entre otras situaciones teórico formales. Pero la subjetividad es un elemento importante, pues nos obliga a meditar o reflexionar y por ende a investigar ciertos fenómenos sociales, es más, gracias a ella podemos comprender y, por qué no decirlo, nos sensibilizamos y autoevaluamos a la sociedad en nuestro relato, pero si no regulamos ello por diversos métodos generaremos un problema como el desborde, el apasionamiento o sobredimensión y por ello el control o la conciencia plena de los investigadores.

\section{El anacronismo}

Otro dilema es el anacronismo, entendido como el hecho de ubicar ciertos elementos en contextos o periodos a los cuales no pertenecen, también puede ser el hecho de dejarnos llevar o contagiarnos del relato en el tiempo y traspolarlo gracias a la subjetividad en otro tiempo e incluso no solo los relatos, las prácticas que a pesar de su vigencia no pertenecen ni tienen el mismo sentido por el cual se crearon o gestaron. Una situación realmente interesante pues gracias a este criterio existe una posibilidad de comprender otra situación que abarca la historia, pues ella no solo estudia a la sociedad a través del tiempo y el espacio, el historiador trata de comprender el cambio que experimenta la sociedad y gracias a la problemática del anacronismo el historiador puede comprender el cambio que experimenta la sociedad pues al tratar de no generar el anacronismo constituye métodos que lo ayudan a construir su relato el cual nos ofrece una comprensión del dinamismo de la sociedad. Ello gracias desarrollo en el relato histórico los criterios de sincronía y diacronía, en el cual se regula y se dota de tiempo dinámico a los fenómenos sociales que describe en el cual ubica o visualiza el transcurso de los sucesos y el cambio en lo que investigamos de la sociedad.

\section{Los elementos de la Historia}

El historiador tiene, como lo mencione líneas arriba, una labor la cual consiste en comprender el cambio que experimenta la sociedad a través del tiempo y el espacio. Ello evidencia algunos elementos; en principio el cambio, una palabra muy usada, que significa pasar de un estado a otro. Pero que es compleja identificar, para ello disponemos de una serie de fuentes y es a través de ellas que podemos identificar el antes y el después, es decir las fuentes como testimonio del paso del ser humano en el tiempo evidencian regularidades, pero en algunos momentos salen de ello y constituyen el inicio de fluctuaciones o nuevas regularidades.

Otro elemento la sociedad y sobre ella podríamos decir que es la composición de individuos que desarrollan en el tiempo múltiples características y fenomenologías complejas en su afán de controlar el espacio que lo rodea, dichas situaciones se encuentran 
reflejadas en los vestigios o elementos que construye en el tiempo y las cuales constituyen una madeja indispensable para nuestra investigación. Lo cual nos lleva al otro elemento la palabra espacio, el cual es el entorno geográfico que transforma el hombre y que a su vez lo afecta en el tiempo, dotándolo de características y contribuyendo en su formación. Un último elemento la palabra tiempo, que no solo es una medida cronológica que utilizamos para ubicar los sucesos que testifican como marcas el paso del hombre.

El tiempo es un elemento enriquecedor al cual por su naturaleza dota de importancia y movimiento a nuestro relato histórico, es tan vital que se le ha constituido una metodología la cual nos ayuda a ubicar a los fenómenos, el tiempo corto, mediano y largo, lo que no es solo un corte cronológico, pues nos permite darle dinámica y espacio a los acontecimientos, procesos y hechos respectivamente. Ello constituye el universo del llamado tiempo del historiador, el cual nos ubica a las categorías en tiempo determinados, en donde el llamado tiempo corto es en donde se desenvuelven los acontecimientos históricos, en donde el acontecimiento se nos aparece gracias al historiador como una descripción diseñada para impactar, pues en realidad delata una acción social de gran importancia que genera un impacto, que posee dinámica, causalidad, resonancia, repercusiones y reproducciones a través del tiempo. Pero que conforme transcurre el tiempo va adaptándose constituyéndose o desapareciendo aparentemente, pues solo está a la espera del historiador que lo rescate de los empolvados anaqueles u espacios de almacenamiento.

Pero un acontecimiento histórico no solo es un suceso de notoria importancia, que marca la continua regularidad de desenvolvimiento de la sociedad, su naturaleza no es suficiente para ver su singularidad, pues entonces todo sería un acontecimiento histórico, mi propuesta es que un suceso se convierte en acontecimiento histórico porque la sociedad no solo lo rememora inmediatamente, sino que lo retrotrae constantemente en el tiempo, por diversos motivos, pero sobre todo porque ha quedado impregnado en el imaginario colectivo por su carácter y su situación radical, lo que nos muestra dos características importantes del acontecimiento histórico, la primera su carácter y su reproducción.

\section{Sobre las fuentes}

Ello nos lleva a comprender otro elemento del historiador que ante el reto de explicar; procesos, hechos, acontecimientos y demás fenómenos históricos, trata de aproximarse a la comprensión de los cambios que experimenta la sociedad a través del tiempo. Se somete ante una realidad fluctuante, a la cual puede aproximarse mediante una serie de principios teóricos y al análisis de una variedad de fuentes, las cuales contienen parcialidades de información de dicha realidad. Ello implica que el historiador debe dominar una serie de métodos para poder extraer el máximo de información posible para realizar un análisis de la sociedad en pro de lo que llamamos una reconstrucción de la historia de una sociedad.

Pero para lograr ello el historiador debe ampliar su comprensión y análisis a las diversas fuentes para poder comprender los fenómenos sociales, dichas fuentes que son los ecos 
de los sucesos acaecidos y que además se van construyendo en el tiempo. Pero también se debe ser consciente que a través del tiempo el historiador a privilegiado algunas fuentes en particular: En un inicio la fuente oral, posteriormente la fuente escrita que incluso marca el origen formal de nuestro oficio y de la cual la mayoría de las investigaciones se ha hecho presente, es esta fuente que hasta la época sigue siendo privilegiada en la mayoría de investigaciones. Pero también no debemos negar que conforme nuestra actividad progresa el uso de fuentes se ha ido diversificando e incluso complementándose con otras fuentes; la oral, la monumental, la pictórica, entre otras. E incluso la investigación histórica ha ido cambiando de fuente privilegiada de acuerdo a la tendencia de la investigación o las diversas formas de hacer historia a través del tiempo.

Ante esta situación mencionada debemos preguntarnos, ¿en el siglo XXI cuál es la fuente que privilegia el historiador? 0 mejor deberemos preguntarnos ¿cuáles serán las fuentes que deberemos usar? La respuesta sería muy compleja, pues el historiador es un ser versátil que desde su inicio intelectual es capaz de comprender esa situación y encontrar ante un problema como este una gran posibilidad. Pues nosotros los historiadores sabemos que todo aquello que ha creado el hombre y lo rodea es una fuente, que posee información y que trasciende incluso nuestra propia existencia.

Las diversas fuentes o testimonios encontramos una veta de información y en donde en la actualidad lo escrito, lo oral, lo audio visual y otras, son fuentes muy importantes, y que en la actualidad al parecer más se producen y reproducen en la sociedad actual e incluso gracias a los avances tecnológicos tienen al parecer mayores alcances en la recepción de la población de este siglo. Es así que lo escrito y lo audiovisual se constituye como los medios más importantes e influyentes por su masividad interactuante y su alcance social principalmente. Ya sea por la prensa escrita, la tv, los documentales y el cine.

A través de estos medios se mantienen, refuerzan y reproducen acontecimientos o fenómenos sociales vigentes y por ello puedo agregar que gracias a estas fuentes los ecos del pasado retumban en el presente, aunque no con la contundencia inicial, pero gracias a la necesidad social se reproduce o mantiene vigente dicha situación que están presentes en el imaginario colectivo. Además de lo escrito líneas anteriores se puede desprender que las acciones o fenómenos sociales se mantienen gracias a estas diversas fuentes, que sirven de refuerzos conscientes o inconscientes de la memoria colectiva y que gracias al impacto en el imaginario colectivo, a través de la información que emite y transmite las nuevas generaciones, en las cuales el relato nos muestra las diferencias de un tiempo a otro.

Puedo agregar que las fuentes que nos aproximan a la descripción de un acontecimiento entretejen múltiples características: una de ellas es que en forma afanosa y sincrónica nos construye una dinámica social con mucha inspiración de la realidad percibida por los creadores, la cual transmite un discurso social de ciertos grupos colectivos de la sociedad, que evidencia un contexto social en la cual está inmerso el suceso o acontecimiento. Otra característica es que las fuentes poseen limitaciones pero también pretenden 

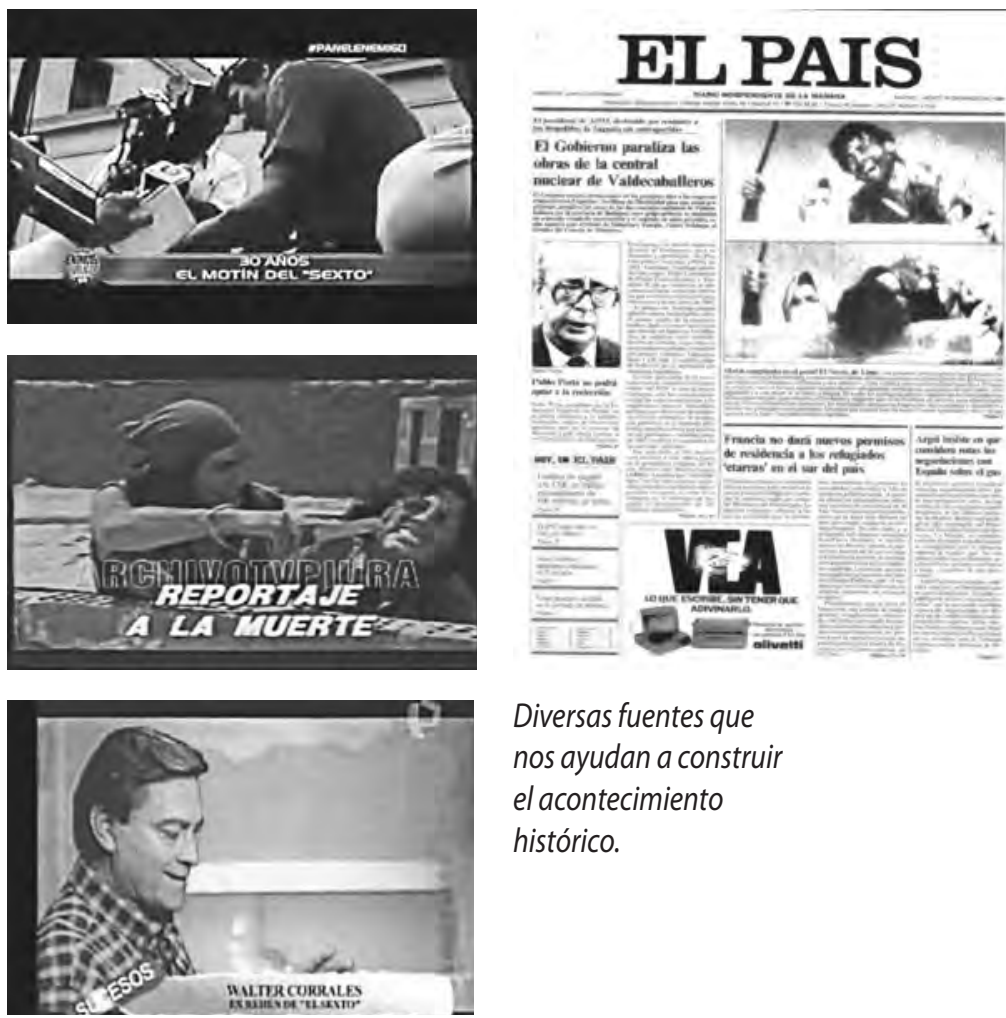

Diversas fuentes que nos ayudan a construir el acontecimiento histórico.

relacionarnos o darnos una lección histórica quizás con la intención de autoevaluación, reflexión, reproducción o simplemente con un fin morboso y sensacionalista de percibir o rememorar una dinámica social.

Es a través de múltiples fuentes por lo cual podemos ingresar al universo del acontecimiento histórico, este suceso o acción humana que tiene una relevancia pues desata una fluctuación que a través del análisis evidencia un antes y un después del suceso y que por su naturaleza sobresaliente es un fenómeno social complejo que espera lentamente la mirada exhaustiva del investigador social, el cual evidencia su impacto no solo por lo que constituye o construye, su resonancia sino también en su reproducción social a través de diversos soportes o medios los cuales son fuentes de información para el historiador.

\section{Una mirada al acontecimiento y su construcción a través del motín en el penal El Sexto}

El'acontecimiento histórico' es un elemento preferido y analizado por el historiador, pues es apreciado como una fluctuación, producto de la alteración de diversas situaciones. Su naturaleza de acción humana sobresaliente y vinculante, lo hace particularmente único, pues puede ser a su vez similar con otros eventos coetáneos o distantes en el tiempo. 


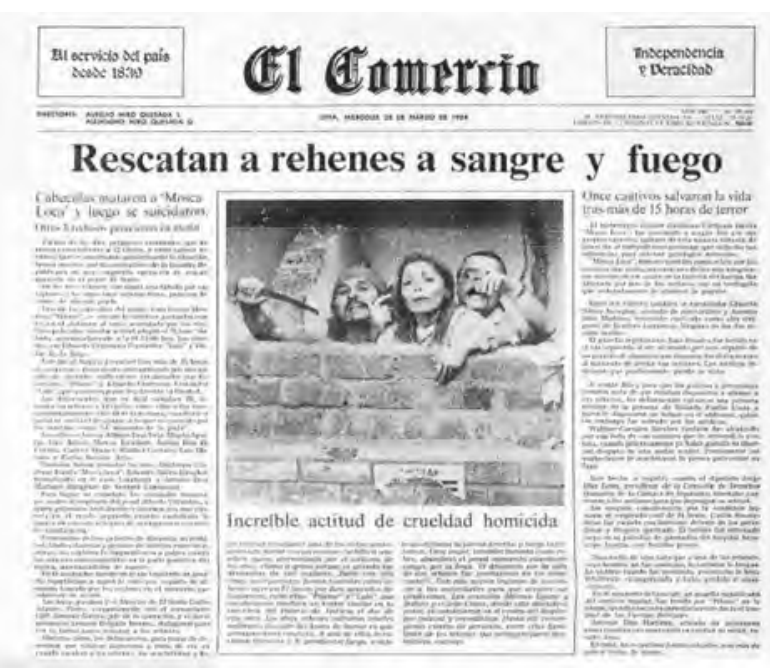

Noticia del acontecimiento histórico (El Comercio, 28 de marzo de 1984).
Para nosotros los historiadores, esta categoría es privilegiada en la investigación, pues es un punto de partida en la comprensión de la dinámica social, ya que posee elementos importantes como: Una ubicación temporal y espacial, además de poder ser describible, definible o ubicable dentro de ciertos criterios de fenomenología social, otro elemento importante de un acontecimiento es la causalidad de su origen que está en constante construcción y por ende su manejo multifactorial hace posible una manipulación del mismo a través de una gran diversidad fuentes que hacen factible apreciarlo desde diversos ángulos o enfoques, también porque un acontecimiento pertenece o puede ser vinculado a una cadena de eventos que responderían a la construcción de una dinámica. A su vez el acontecimiento posee una forma en la cual se afirma en la sociedad a través de elementos de reproducción social; tradición, costumbres, monumentos, y cualquier otro medio que pueda rememorar el suceso.

\section{El motín del penal El Sexto}

Partiendo de estas ideas líneas anteriores iniciare la descripción de un acontecimiento histórico que se desarrolló en el Perú de los años 80 del siglo XX una época muy intensa por los múltiples fenómenos complejos gestados por la sociedad de aquellos años, tales como: Crisis económica, problemas políticos, crecimiento desmesurado y descontrolado de la población, aumento de la criminalidad, terrorismo, entre otros. Es en este contexto en el cual se desarrollan una serie de acontecimientos que impactan en nuestra sociedad y cuyo recuerdo aún se mantiene en nuestro imaginario peruano. Tal como el ocurrido el 27 de marzo de 1984 en la ciudad de Lima, el motín al penal el Sexto, el cual es cubierto por la prensa escrita y con un despliegue único en la historia de la televisión nuestro país pues, el desarrollo de este suceso se sigue en vivo y en directo en señal abierta, a nivel nacional y con repetidoras a nivel internacional. Es a través de este medio por lo cual la sociedad limeña ve con sus propios ojos el descontrol, el desgobierno y como se trasluce el incremento de la violencia y de la delincuencia incontenible e irreformable en nuestro 


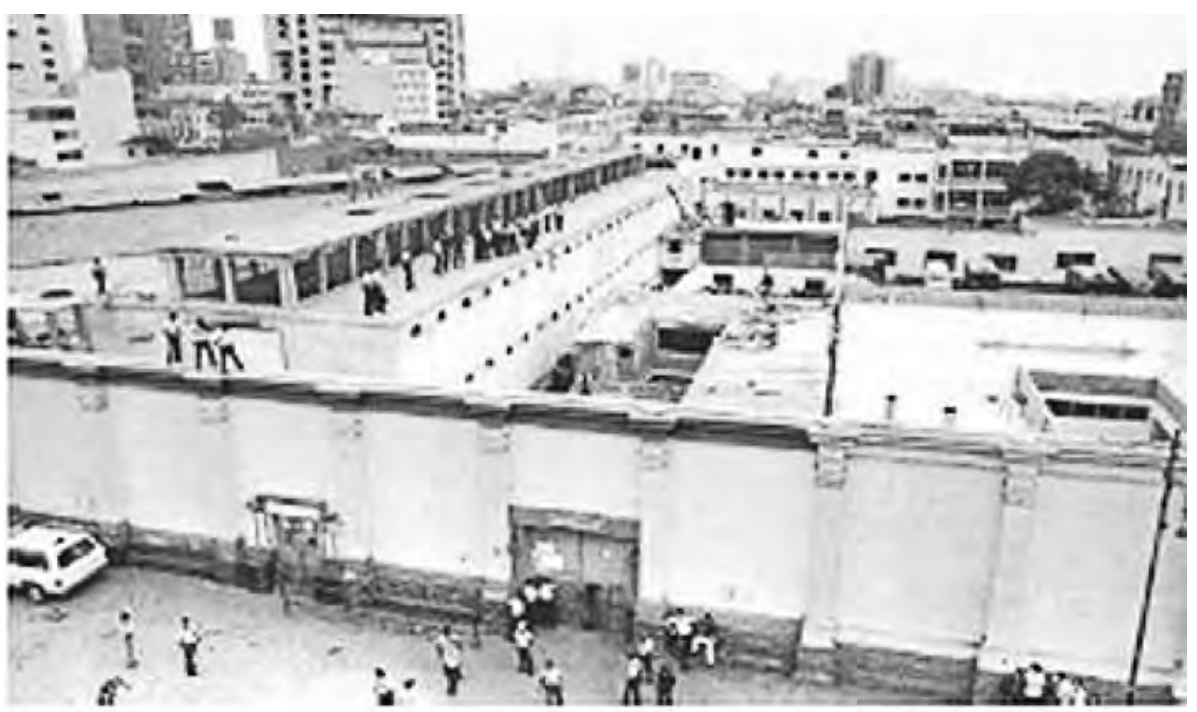

Imagen de las instalaciones del penal El Sexto (El Comercio, 28 de marzo 1984).

país, ello a través del ingreso de dicho cuadro episódico violento en los hogares a través de la televisión.

Según la televisión y la prensa escrita la ciudad de Lima vivió las 15 horas más intensas. Pues aproximadamente las 10:45 de la mañana del 27 de marzo de 1984 un grupo de reos de alta peligrosidad integrados por: "Luis García Mendoza (a) Pilatos, Eduardo Centenaro (a) Lalo, Luis Carbajal Polanco (a) Carioco, José Gonzales Zavaleta, Jorge Tarazona (a) Papi y Luis Wong Arteaga a los que se les sumaron otros reclusos."2 Los cuales habían realizado un levantamiento en el interior del penal El Sexto, en dicha situación los reclusos en mención tomaron como rehenes a trabajadores de dichas instalaciones(dos trabajadoras sociales, dos abogados, dos psicólogas, una secretaria, tres empleados de establecimiento de penales) e iniciaron una serie de exigencias y generaron una situación de: tensión, victimización, tortura y crimen en contra de algunos de los rehenes. Dicha situación se desarrolló por más de 15 horas en el interior de dicho establecimiento penitenciario ubicado en el cercado de Lima entre el cruce de la hoy avenida Alfonso Ugarte, la Av. Bolivia, Av. Uruguay y el Jr. Chota.

Este suceso es considerado como acontecimiento por múltiples razones como: la violencia, la sublevación de los reos ante las autoridades de la institución, pero sobre todo la cobertura de dicho levantamiento y el despliegue de la violencia por parte de los medios de comunicación que van a darle mayor énfasis y sobredimensionamiento social en donde los espectadores y sobre todo por los actores gracias a ello van a constituir un desenvolvimiento único que va a constituir una serie de reproducciones sociales en el tiempo.

2 La Crónica (28 de marzo 1984) Lima.. 
Y que gracias al enfoque de la historia del imaginario podemos comprender que es un acontecimiento histórico a partir de la construcción de sus medios de resonancia y reproducción, además de la típica descripción de su naturaleza cuya connotación radica en su importancia o impacto, el cual nos muestra causas y sus efectos y como se afirma en la sociedad. Si observamos el motín del penal del sexto desarrollado un 27 de marzo de 1984 en la ciudad de Lima como un acontecimiento histórico, que marca violentamente a la sociedad limeña y que es recordado por muchos años ${ }^{3}$.

Desarrollando una descripción sincrónica, este suceso desarrollado en la década de los 80 del siglo XX, es producto de diversas situaciones complejas como: el desborde poblacional de ciudad de Lima, una ciudad agotada por la crisis económica y la reorganización de un gobierno civil, además de ello una sociedad dispersa, dividida y con muchos espacios marginados o marginales, pugnas violentas, inseguridad ciudadana, un elevado índice delincuencial y producto reformas judiciales y penitenciarias sin mayor efectividad para frenar la violencia o criminalidad e incluso la reinserción social, elementos como por ejemplo; la supresión de pena capital para delitos graves que afectan a la ciudadanía y la reforma penitenciaria no fueron suficientes para la reinserción social, entre otros.

Pero este acontecimiento tiene como causas directas la ineficacia del sistema penitenciario, que desde 1980 a marzo de 1984 se habían registrado 15 motines o intentos de fuga todos ellos con lamentables escenas de violencia y muerte, incidentes que marcan el defecto e ineficiencia de las instituciones de orden y justicia en el Estado y a su vez el desborde la delincuencia en nuestro país en esa década. Pero un incidente violento similar perpetrado de los delincuentes antes mencionados, puede ser una situación causal directa el 2 de marzo de 1984 en la carceleta del Poder Judicial mantuvo a dos rehenes entre ellos el forense y un oficial de la guardia republicana en la cual tuvieron por más de 27 horas los funcionarios de la institución en calidad rehenes en las instalaciones exigiendo vehículos para escapar y que finalmente fueron controlados por la policía, pero por la lenta administración de justicia fueron trasladados hasta que puedan tener sentencia efectiva a la prisión más cercana a pesar de su peligrosidad, ello fue la deliberación del fiscal B. Madueño Yansey, el cual es acusado por el director de establecimientos penitenciarios Miguel González del Río como el causante directo, pues en su opinión el susodicho fiscal después de los incidentes del 2 de marzo de 1984 llego a un acuerdo con dos de los cinco delincuentes que tomaron a los rehenes en la carceleta del poder judicial ellos son "Pilatos y Lalo", los diarios del 28 al 29 de marzo informan de ello y creen un supuesto favoritismo motivado por relaciones con una red de corrupción, delincuencial o de narcotráfico.

Otra causal importante pero distante son los 15 incidentes penitenciarios en los diversos penales de Lima incluso el del penal Lurigancho desarrollado el 17 de enero de 1984 donde murieron ocho reos y una religiosa y otro desarrollado en el mismo penal del sexto en el cual una gresca entre bandos criminales termina no solo con la vida de reos

3 Sobre este acontecimiento la prensa escrita y audiovisual han escrito mucho sobre; el escenario, el ambiente, los personajes y la problemática social y legal de la época. Para ello puede verse la información registrada en la bibliografía. 


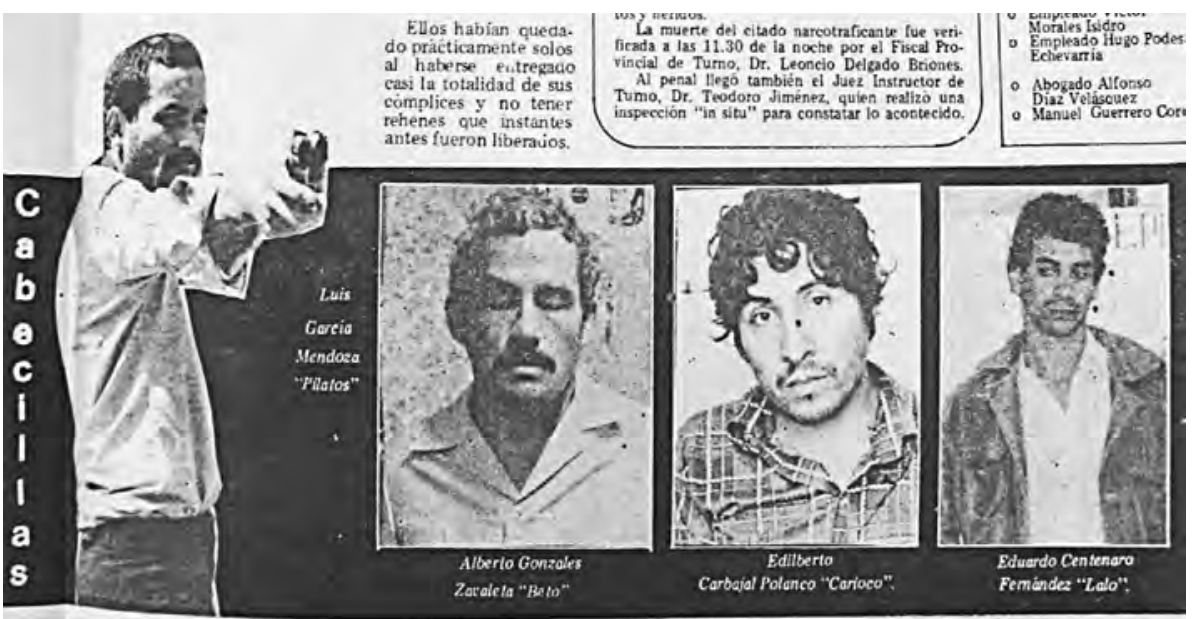

Imagen de los cabecillas del motín (La Crónica, 28 de marzo de 1984).

sino con un levantamiento de criminales ello el 4 de marzo de 1981 en las cuales los dos bandos que controlan la prisión los de Lima y los Chalacos, desarrollan una gresca violenta con un impacto de más de una decena de muertos y heridos, todos ellos criminales de la prisión, pero ello revela la incapacidad de contener o repeler efectivamente la violencia en el interior de los penales y sobre todo que el poder del orden interno no radica en los la policía sino también en los comités conformados por los reos y sus líderes.

El motín del 27 de marzo de 1984 se convierte en todo un acontecimiento violento por el despliegue de tortura, sadismo y crimen que es transmitido en cadena nacional en vivo y en directo, situación que después de 15 horas que desarrolla los siguientes eventos cargados de violencia que fue cubierto en vivo y en directo por la televisión y reforzado por la misma televisión y la prensa durante los días consecutivos al incidente, un recuento de las acciones en el acontecimiento seria tentativamente el siguiente:

A las 10:00 a.m. una decena de reclusos toman como a 12 trabajadores de las instalaciones del penal, hiriendo en el muslo a Alfredo Villalobos Machado para obligarlo a abrir la puerta que los llevaría a los demás trabajadores que serían captados, además realizan la detonación de un cartucho de dinamita hiriendo en el ojo izquierdo al guardia republicano Luis Rosales.

11:50 hace su ingreso en la escena en representación del poder judicial el doctor Leoncio Delgado Briones de la tercera fiscalía provincial para interponer sus oficios y visualizar el panorama a su vez las televisoras como PANTEL y AMÉRICA inician la transmisión en vivo y en directo ya 40 minutos antes estaban proyectando imágenes del exterior y comentando sobre el incidente pero cobra atención cuando a los 5 minutos a las 11:55 hacen estallar un segundo petardo en la puerta del penal, lo cual llama la atención de los medios de comunicación, pues no solo suponen que son reos sino que posiblemente un atentado terrorista o la gran fuga de dos reos de alta peligrosidad por un lado el agente senderista Antonio Díaz Martínez y por otro lado Guillermo Cárdenas Dávila "Mosca Loca" 


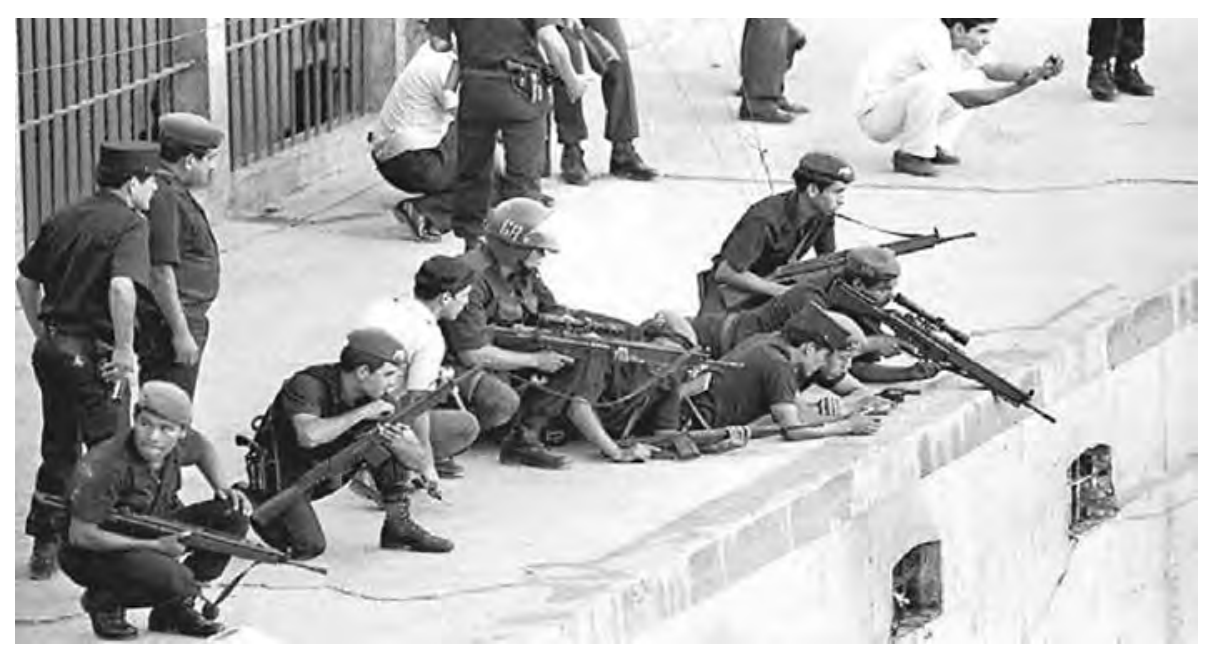

Posicionamiento del batallón "Yapan Atic" (La Crónica, 29 de marzo de 1984).

uno de los más grandes narcotraficantes del país que vivía en el interior del penal con muchos privilegios según escribirán los diarios de la época pero su relevancia es porque ofreció al gobierno del presidente Belaunde que el pagaría la deuda externa del país si lo dejaban continuar con su trabajo de traficante de drogas.

A las 12:10 minutos llegan al lugar el batallón de la guardia republicana "Yapan Atic" (que todo lo pueden) dirigidos por el comandante Antonio Gálvez S., ellos con un equipo de francotiradores y expertos en tácticas antisubversivas y crimen se dispone de las partes altas y de lugares estratégicos preparándose para que el incidente no escape de los muros del penal. A su vez otros que se van apoderando de los techos de los edificios aledaños son los reporteros gráficos y los canales de televisión nacional y corresponsales extranjeros.

Entre las 12:30 y 13:00 horas van reuniéndose las distintas autoridades como el prefecto, el fiscal, el director del penal y el fiscal superior con el equipo de asalto para ver la situación y deliberar las acciones pero aun los reos no han hecho mayor denuncia de sus intenciones y la situación es confusa aun pues no tiene una información pormenorizada.

Entre las 13:00 y 13:30 horas los reclusos hacen llegar su petición por medio de una nota que envuelve una roca en la cual los periodistas apostados a los alrededores encuentran y pronuncian "estamos bien y los rehenes también, dennos vehículos para salir del penal y no les haremos daños" de lo contrario comenzaremos a "quemar gente". Después de 30 minutos se vuelve a amenazar con prender fuego a los rehenes, pero en esos instantes en que los miembros del escuadrón especializado apostados en el techo avizoran a uno de los rehenes con el rostro ensangrentado, ante ello la fiscalía decide llamar más oficiales y reforzar el cordón policial y tratar de que los familiares y la prensa no se expongan ni hagan mayor alboroto, situación que no se puede controlar.

Pero es a las 13:55 que los presos hacen efectivas sus amenazas vierten keroseno sobre el cuerpo maniatado y golpeado y con sangre en el rostro de Carlos Rosales Arias 
y le prenden fuego ante las exigencias de libertad y amenaza de la integridad de los demás rehenes, el herido minutos más tarde es retirado al hospital de las fuerzas armadas, lo impactante es que la escena es captada en cadena nacional por la televisión es así que la violencia ingresa a los hogares y los reos que tenían una televisión en el interior del penal se ven a sí mismos como los protagonistas y su morbo

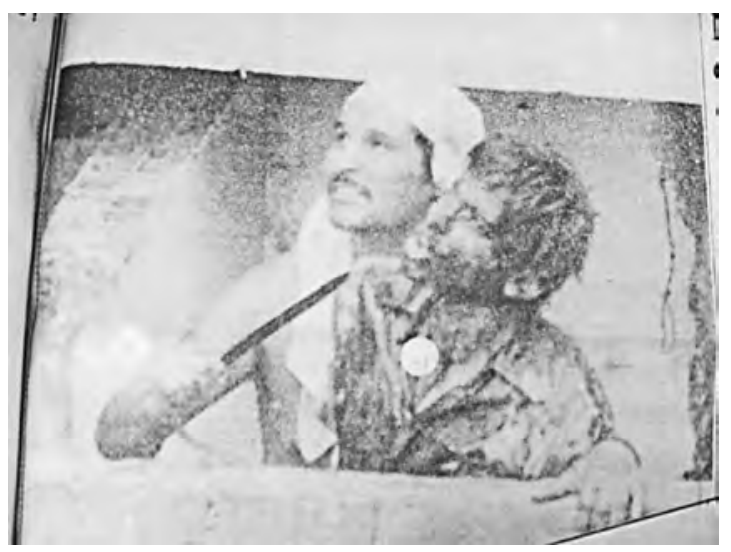

Imágenes de tortura física previo a quemarla (El Comercio, 29 de marzo de 1984). se incrementa lo cual hace más radical su exigencia y determinación. 20 minutos más tarde nuevamente los reos envían una nota escrita a mano en la cual exigen "dos camionetas cerradas, que se les despejen un camino que no los siga ningún policía, pues sino matarían a los rehenes a tiros (lo cual revela que ya tienen armas)" posteriormente otra nota escrita al parecer por un rehén de apellido Díaz dice "no es justo que nos sacrifiquen por no negociar. Tenemos hijos. Les suplicamos que sean más comprensivos y hagan lo que les piden los presos". A lo cual las autoridades no pueden hacer más que observar estupefactos e impotentes como la sociedad peruana que a través de la televisión visualiza un evento cargado de violencia e impotencia.

Pero, si el ultraje físico y las quemaduras no eran suficientes, los captores colocan en la parte superior de uno de los techos del penal a la siguiente víctima, Rolando Farfán Cosio recibe un balazo en el abdomen ante la mirada de los lentes de cámaras fotográficas y filmadoras que hacen posible el ingreso de esa imagen desgarradora a los hogares. Y los reos continúan con sus exigencias, lo extraño es que no dan un plazo de tiempo en todos los comunicados, al parecer ellos solo están atacando y violentando a los empleados de seguridad interna, algunos diarios como La Crónica y El Comercio presuponen ello, en la edición del 28 de marzo suponen que los reos se están vengando de los funcionarios dentro del penal, más de

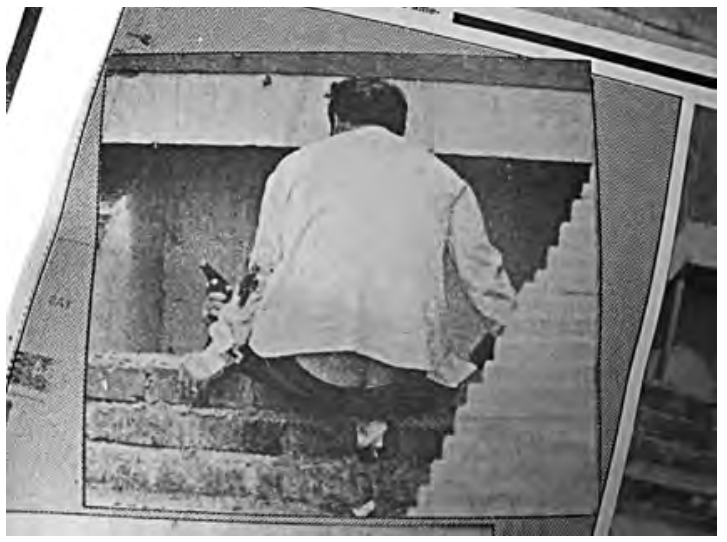

Imagen antes de dispararle al rehén (La Crónica, edición especial, 29 de marzo 1984). 
dos décadas después los documentales suponen ello y revelan que los reos tiene armas al parecer por la corrupción interna.

Posteriormente a las 16:25 minutos se inicia fuego en la sección de enfermería, no se sabe quién origina el incendio algunos suponen que hay pugnas interna entre reos ello lo plantea la televisión, y traen a colación las pugnas por el poder en el interior de los penales por parte de los sectores de limeños y chalacos, tal como lo ocurrido años antes. Además el cerco policial a los alrededores del penal no puede contener a curiosos, periodistas y familiares de los reos los cuales piden que se hagan esfuerzos para que todos estén sanos y salvos, los familiares piden que sus seres queridos no sean asesinados por lo policías. A las 17:50 llega a uno de los techos del penal Jorge Díaz León de la comisión de derechos humanos y de la cámara de diputados del Estado peruano, para solicitarles a los delincuentes desistir de sus actos violentos a las 18:00 los efectivos de la guardia republicana efectúan disparos al aire, pues observan atónitos cómo torturan a golpes a uno de los reos por 10 minutos, luego colocan en la parte superior de uno de los techos, la repetición del mismo ritual, para violentar ante cámaras y la impotencia de las fuerzas del orden, a Walter Corrales Sánchez, el cual realiza un movimiento y ya cuando al parecer ya se liberó de sus captores es cogido de una pierna y es apuñalado repetidas veces, hasta que el efectivo coge una barra de metal y logra liberarse pero otro delincuente le dispara, luego a las 18:25 después de 15 minutos de violencia logra liberarse y es llevado al hospital.

Ya habían pasado más de seis horas y la violencia era incontrolable, se le corta el rostro a una de los rehenes y se le obliga a otra a violentar con un puñal a un hombre y que proclame las exigencias de los reos, a las afueras del penal las autoridades deciden despejar la zona utilizando Rochabús (vehículo policial que dispersa a la población insurgente con potentes chorros de agua), lo presos envían un comunicado a las 19:00 horas con plazo de duración de 30 minutos para cumplir con sus exigencias o mataran a sus rehenes, a las 20:00 al parecer las autoridades van a cumplir les habían dicho que van a colocar ambulancias y camiones de bomberos en las puertas y una ambulancia anuncia con el sonido de su sirena el corte del fluido eléctrico en la zona y se restringe la transmisión de la prensa, a las 21 horas y 50 minutos los efectivos de la guardia republicana el batallón Yapan Atic inicia el rescate con lanzar bombas lacrimógenas y se inicia la balacera y liberación de los rehenes, y la captura de cabecillas que luego se informa que se suicidaron al ser trasladados por la policía.

Horas más tarde los hospitales de la ciudad tienen más de sesenta heridos y más de una docena de muertos, el titular de la crónica y del diario el comercio del 28 de marzo de 1980 comenta el resultado 12 muertos y más de 60 heridos, en más de 15 horas de terror, meses más tarde se traslada los reclusos y el penal es cerrado, además sociopolíticamente se está trayendo a debate la reincorporación de la pena de muerte y la construcción de nuevos penales. Además de que la violencia ingreso directamente gracias a los medios de comunicación. 


\section{A manera de conclusión preliminar}

El motín en el penal "el Sexto" desarrollado el 27 de marzo de 1984, es considerado todo un acontecimiento histórico, pues este suceso se convierte en sobresaliente, por ciertas situaciones principalmente. La primera, por la violencia que desata en pocas horas, la cual es trasmitida por diversos medios de comunicación y en particular por la televisión que realizo por primera vez una cobertura en vivo y en directo sin ninguna restricción lo cual provocó en un ingreso directo de la violencia en los hogares del Perú y el extranjero. La segunda razón radica en la reproducción social del incidente, pues no fue solo cubierto por los medios de comunicación en solo el día que sucedió, sino que fue noticia por semanas, meses e incluso en años es recordado a través de notas periodísticas o especiales televisivos que equiparan sucesos similares. Posteriormente años más tarde fue base de un filme peruano "Reportaje a la muerte", también fue motivo de publicaciones y documentales a los 30 treinta años.

Esta acción humana posee todos los elementos de un acontecimiento e incluso la capacidad de inserción social a través de los medios de comunicación masiva como documentales, reportajes e incluso un filme. Fuentes que son una gran oportunidad para el historiador, pues están cargadas de gran subjetividad, pues ellas no solo reconstruye a su manera un acontecimiento, fusiona también elementos sociales complejos u otros acontecimientos, guarda múltiples objetivos. Pero sobre todo traslada elementos sensibles del imaginario de la sociedad como; lenguaje, gestos, costumbres, actitudes plasmadas por los actores, situaciones que escapan a la fuente escrita y que se encuentran en la sociedad oculta en sus expresiones materiales del imaginario.

Estas fuentes son la producción que se basa en el acontecimiento histórico del motín en el penal de El Sexto, realizado en marzo de 1984, que nos trasluce el incremento de la violencia y delincuencia incontenible e irreformable en nuestro país, y como dicho cuadro episódico violento ingresa en los hogares a través de medios de comunicación masiva como la televisión que despliega el reportaje al motín en el Penal del sexto en vivo y en directo, una cobertura realizada por primera vez en la televisión peruana realizado en la semana santa del año de 1984.

Este acontecimiento posee todos los elementos que lo constituyen como un acontecimiento, lo principal seria dos situaciones; la primera posee los componentes de su naturaleza, me refiero a los elementos de impacto, las circunstancias, el impacto y el efecto inminente o inmediato. Y lo segundo es las formas o medios de resonancia y reproducción social.

En cuanto al primer sentido los actores fueron: Los amotinados, los rehenes, familiares, autoridades, la sociedad expectante, la prensa televisiva, entre otros, de los cuales la prensa televisiva juega un papel importante pues nos muestra el negocio en el cual se va a convertir hacer prensa televisiva sensacionalista en nuestro país en la década de los 80 'y como ella construye los acontecimientos históricos, arriesgando, no midiendo el impacto social 




Una de las consecuencias el replantear la Pena de Muerte. (El Comercio 29 de marzo 1984)

en la población y la actitud sociópata de los reos que se ven a símismos en la televisión, no solo nos muestra una prensa cumpliendo su labor sino los conflictos éticos y económicos que se construyen en el desarrollo de su labor y como la violencia ingresa en vivo y en directo a los hogares limeños gracias a la prensa en busca del llamado rating, sin medir el grado de morbo social al cual va a acostumbrar a la población peruana y cuyos ecos repercuten hasta la actualidad.

Las fuentes nos ingresan a un momento donde imperan ciertos aspectos de la sociedad limeña de aquella época en donde destacan: la inseguridad ciudadana, el aumento de la criminalidad en nuestro país, las deficiencias del sistema penitenciario y la policía, ante la temeraria actitud de la delincuencia recluida en los penales, situación muy frecuente, pues en nuestro país el control interno de los penales es desarrollado por los propios reclusos y sus asociaciones delictivas en donde los pabellones están dirigidos y marcados por los lugares de origen y la peligrosidad o grado de criminalidad. En donde el recluso del penal es un personaje desadaptado, despiadado producto de la circunstancias y sobre todo irreformable.

Un elemento muy importante que se evidencia en este acontecimiento es mostrar las consecuencias mediáticas del abordaje de las noticias, pues muestra el desconcierto social de los parientes de los reos, la actitud limitada por horas de las fuerzas del orden, e incluso la des credibilidad del poder judicial y el impacto psicológico que crea la prensa en los reos, pues estos reporteros puesto que al transmitir en vivo los actos violentos de los presos, los están presenciado por televisión en el penal y les están dándole demasiado protagonismo a estos delincuentes. Cuando deciden cortar la transmisión en vivo, ya es muy tarde, ahora los presos se sienten mismo actores de película de acción "... estos individuos son un colectivo violento que se sienten héroes y se estimulan cuando se ven en televisión..." y piensan llegar hasta las últimas consecuencias comportándose violentamente con los rehenes, situación que en la vida real es presenciada a través de la televisión, prensa escrita, documentales y que el filme reproduce dichos actos de violencia.

A su vez el aconteciendo nos revela cómo su contundencia no solo radica en su carácter singular sino también en la capacidad de reproducción social, lo cual a través de las fuentes se puede evidenciar, a su vez se puede percatar a través de las mismas la existencia de un antes y después. Pero hay algo que resulta ser un terreno aún en tinieblas en mi explicación, pero conforme se desarrolla mi proyecto de tesis se va clarificando, es el hecho de que existe una situación importante, en principio las fuentes oficiales desprenden un 
relato y por lo tanto la construcción de un acontecimiento histórico, pero existe una fuente el rumor, la cual se encuentra en la vía oral y que utilizando la base de la fuente oficial y otros soportes se desprende y se construye otro relato en la cual existe una conspiración o una cortina de humo, para cubrir la supuesta huida de Guillermo Cárdenas Dávila"Mosca Loca" a quien, según la información oficial y testigos, vieron muerto, pero el imaginario ve una conspiración, un plan para la fuga en la cual todos los elementos se integran y dan como resultado una fuga limpia y una supuesta muerte. Ello constituye también parte del acontecimiento histórico, pues la sociedad construye en diversos soportes la reproducción del suceso y lo refuerza en el tiempo, situación que no escapa a este suceso que no brinda los elementos característicos de una categoría que la historiografía debe contribuir en construir ciertos alcances para comprender su dinámica.

\section{Fuentes y bibliografía}

\section{Fuente escrita}

El Comercio. (31 de marzo de 1984). Lima.

El Comercio. (29 de marzo de 1984). Lima.

El Comercio. (28 de marzo de 1984). Lima.

El Comercio. (30 de marzo de 1984). Lima.

La Crónica. (31 de marzo de 1984). Lima.

La Crónica. (30 de marzo de 1984). Lima.

La Crónica. (29 de marzo de 1984). Lima.

La Crónica. (28 de marzo de 1984). Suplemento especial. Lima.

\section{Fuente audiovisual}

"Reportaje a la muerte" producido por Casa Blanca Films S.A. Lima 1993

Reportaje de 24 horas edición especial. PANTEL. Lima, 27 de marzo de 1984

Reportaje de América Televisión. Lima, 27 de marzo de 1984.

Edición especial de Pulso. Lima, marzo de 1984.

Detrás del Crimen. "MOTín EL SEXTO" Panamericana Televisión S.A. Lima 2009.

Documental Sucesos. "La sangrienta historia del motín del sexto contada por quienes sobrevivieron" Panamericana Televisión S.A. Lima 2012.

\section{Bibliografía}

AguiRRE RojAS, C. (1996). Fernand Braudel y las ciencias humanas. Barcelona: Montesinos. AguiRRE RoJAS, C. (1999). La escuela de Annales. Madrid: Montesinos. 
ANDERSON, P. (1996). Los fines de la historia. Barcelona: Anagrama.

ARÓSTEGUI, J. (2001.) La investigación histórica: teoría y método. Barcelona: Crítica.

BLOCH, M. (2001). Apología para la historia o el oficio de historiador. México: Fondo de Cultura Económica.

BRAUDEL, Fernand (1953). El Mediterráneo y el mundo mediterráneo en la época de Felipe II. México, D.F.: Fondo de Cultura Económica.

BRAUDEL, Fernand (1968). La Historia y las ciencias sociales. Madrid: Alianza.

BRAUDEL, Fernand (1969). Las civilizaciones actuales. Estudio de historia económica y social. Madrid: Tecnos.

BraUdeL, Fernand (1974). Civilización material, economía y capitalismo. Siglos XVI-XVIII. Madrid: Alianza Editorial.

BraudeL, Fernand (1989). El Mediterráneo: el espacio y la historia. México, D.F.: Fondo de Cultura Económica.

BRAUDEL, Fernand (1991). Escritos sobre la historia. México, D.F.: Fondo de Cultura Económica.

BURGUIĖRE, A. (1993). «Historia de una historia: el nacimiento de Annales». En Pagano, N. y Buchbinder

P. (Comp.), La historiografía francesa contemporánea(pp. 79 - 100) Buenos Aires: Biblos.

BURKE, P. (1993). La revolución historiográfica francesa. La escuela de Annales, 1929-1989. Barcelona: Gedisa.

CANNADINE, D. (Ed.). (2005). ¿Qué es la historia ahora? Granada: Editorial Universidad de Granada.

CARR, E. H. (1961). ¿Qué es la Historia? Barcelona: Ariel.

CLemente RAMOS, J. (1989). Consideraciones sobre la teoría histórica de la escuela de Annales».En Anuario de Estudios Medievales, 19, pp. 17-25.

DosSE, F. (1988). La historia en migajas. De «Annales» a la «nueva Historia». Valencia: Institució Valenciana d'Estudis i Investigación

FontANA LÁZARO, J. (1996). La historia después del fin de la historia. Barcelona: Crítica.

HeLleR, A. (1991). Historia y futuro: ¿sobrevivirá la modernidad? Barcelona: Ediciones Península.

HELLER, A. (1999). Una filosofía de la historia en fragmentos. Barcelona: Gedisa.

MORADIELLOS, E. (2001). Las caras de Clío. Una introducción a la historia. Madrid: Siglo XXI de España.

VÁZQUEZ GARCíA, F. (1989). Estudios de teoría y metodología del saber histórico. De la escuela histórica alemana al grupo de los «Annales». Cádiz: Universidad de Cádiz.

WALleRSTEIN, I. (1993). «Fernand Braudel. Homme de la Conjoncture», en N. Pagano y P. Buchbinder (comp.), La historiografía francesa contemporánea, Buenos Aires, Biblos, 1993, pp. 131-151.

WHITE, H. (1995). Meta-história: a imaginação histórica do século XIX. São Paulo: Editora da Universidade de São Paulo.

WHITE, H. (1992). El contenido de la forma: narrativa, discurso y representación histórica. Barcelona: Paidós.

WhITE, H. (1991). "Teoría literária e escrita da história". En Revista Estudos Históricos, vol. 7, n. 13, 1991, p. 21-48. Recuperado de: http://bibliotecadigital.fgv.br/ojs/index.php/reh/article/ view/1978/1117 
